\title{
EFEITO DO NIÓBIO NO COMPORTAMENTO MICROESTRUTURAL DO AÇO INOXIDÁVEL ASTM 409 BI ESTABILIZADO AO TI E Nb EM COMPARAÇÃO A UM AÇO ASTM 409 MONO-ESTABILIZADO AO Ti *
}

\author{
Ricardo José Gonçalves Costa \\ Hélio José Batista Alves ${ }^{2}$ \\ Tarcísio Reis de Oliveira ${ }^{3}$ \\ Berenice Mendonça Gonzalez ${ }^{4}$
}

\section{Resumo}

A estabilização do aço inoxidável ferrítico ASTM 409 na aplicação em sistemas de exaustão de automóveis é cada vez mais exigida em função do aumento das garantias e de desempenho neste sistema, particularmente em temperaturas mais elevadas dos gases de escape. O Ti é um dos elementos mais utilizado como estabilizante da estrutura ferrítica. No entanto, teores elevados deste elemento pioram as condições de lingotabilidade durante a produção do aço, aumentando a sua suscetibilidade a problemas de qualidade superficial. Desta forma, a dupla estabilização com Ti e Nb é uma solução para reduzir o teor de titânio. Assim, o objetivo deste trabalho foi investigar o efeito da adição de $\mathrm{Nb}$ na microestrutura por meio da comparação entre o aço ferrítico estabilizado ao $\mathrm{Ti}(409 \mathrm{H})$ e bi-estabilizado ao $\mathrm{Ti}$ e $\mathrm{Nb}$ (409S). Os resultados deste trabalho mostraram que o aço 409S é afetado diretamente pela microestrutura mais deformada após laminação a quente em relação ao aço $409 \mathrm{H}$, gerando maior força motriz para recristalização no recozimento final.

Palavras-chave: Aços inoxidáveis; Estabilização; ASTM 409; Recristalização.

\section{EFFECT OF NIOBIUM IN THE MICROSTRUCTURAL BEHAVIOUR IN THE STAINLESS STEEL ASTM 409 DUAL-STABILIZED BY TI AND NB COMPARED TO STEEL ASTM 409 SINGLE-STABILIZED BY TI}

\section{Abstract}

The stabilization of the ferritic stainless steel ASTM 409 in the application in automobile exhaust systems are increasingly demanded due to the increase of the performance guarantees and this system particularly at higher exhaust gas temperatures. Ti is one of the most used elements such as stabilizing the ferritic structure. However, high contents of this element worsen the conditions of castability during steel production, increasing their susceptibility to surface quality problems. Thus, the dual stabilized with $\mathrm{Ti}$ and $\mathrm{Nb}$ is a solution to reduce the titanium content. The objective of this study was to investigate the effect of adding $\mathrm{Nb}$ in the microstructure by comparing the ferritic steel stabilized $\mathrm{Ti}(409 \mathrm{H})$ and bi-stabilized $\mathrm{Ti}$ and $\mathrm{Nb}$ (409S). The results of this study showed that 409S steel is directly affected by the more deformed microstructure after hot rolling against the $409 \mathrm{H}$ steel, creating greater driving force for recrystallization in the final annealing.

Keywords: Stainless steel; Stabilization; ASTM 409; Recrystallization.

\footnotetext{
Tecnólogo de Soldagem, Estudante de Mestrado, UFMG, Pesquisador, Aperam South America, Timóteo, MG, Brasil.

2 Físico, Mestre, Pesquisador, Aperam South America, Timóteo, MG, Brasil.

3 Engenheiro Mecânico, Doutor, Pesquisador, Aperam South America, Timóteo, MG, Brasil.

4 Física. Doutora, Professora, Universidade Federal de Minas Gerais, Belo Horizonte, MG, Brasil.
} 


\section{INTRODUÇÃO}

$\mathrm{Na}$ indústria automotiva, o aço inoxidável ferrítico ASTM 409 foi desenvolvido há mais de 30 anos especificamente para aplicação em sistema de exaustão de automóveis, onde é amplamente utilizado. As primeiras versões deste aço atendiam às especificações de estabilização, particularmente com titânio de acordo com os teores exigidos pela norma ASTM A240, conforme estequiometria estabelecida pela relação $[\% \mathrm{Ti}=6(\mathrm{C}+\mathrm{N})]$ [1]. No entanto, estes teores não eram suficientes para evitar falhas, principalmente nas juntas soldadas, devido a problemas de corrosão intergranular.

O titânio, por possuir maior afinidade pelo $\mathrm{C}$ e $\mathrm{N}$ formando carbonetos e/ou carbonitretos de cromo $\left[\mathrm{Cr}_{23}(\mathrm{C}, \mathrm{N})_{6}\right]$, e também pelo menor custo, é um dos elementos mais utilizados como estabilizante da estrutura ferrítica, prevenindo a ocorrência de sensitização, de modo a evitar que o material sofra falhas por corrosão intergranular [2][3]

Entretanto, nos últimos anos, a temperatura do sistema de exaustão tem sido cada vez maior, contribuindo para que o conversor catalítico (catalisador) reduza a quantidade de gases nocivos (NOx, SOx, HC) emitidos ao meio ambiente.

Esta temperatura mais elevada torna o ambiente mais agressivo, exigindo do material maior resistência à corrosão, consequentemente, maiores teores de elementos estabilizantes [2][4].

A partir de 2009 foi desenvolvido pela Aperam South America, o aço 409H (UNS S40920), também estabilizado com Ti, porém, com teores mais elevados visando garantir um maior nível de estabilização exigido pela sua nova aplicação para o sistema de exaustão. Contudo, de acordo com SILVA [5], teores elevados de Ti no aço inoxidável ferrítico 409, podem comprometer a sua produção durante o lingotamento e sua qualidade superficial no produto final com ocorrências de defeitos superficiais do tipo esfoliação.

Uma alternativa é fazer uso da bi-estabilização, utilizando $\mathrm{Ti}+\mathrm{Nb}$, sendo uma solução que vem sendo desenvolvida pela empresa Aperam, visando reduzir o teor de titânio e adicionando pequena quantidade de nióbio.

A adição de nióbio bloqueia a migração dos contornos de grãos devido à segregação de átomos do soluto para o contorno de grão, atrasando a recristalização por efeito pinning (dificuldade do contorno de grão para se liberar de precipitados que impedem sua migração) [6][7].

O projeto de liga do aço denominado 409S (UNS S40930), é concebido de modo a garantir as propriedades adequadas para as suas aplicações no mercado, principalmente a estabilização, de modo a prevenir a corrosão intergranular, conforme especificado na norma ASTM com $(\mathrm{Ti}+\mathrm{Nb}) \geq 0,08+8(\mathrm{C}+\mathrm{N})[1]$.

Assim sendo, o objetivo deste trabalho foi investigar o efeito da adição de $\mathrm{Nb}$ na microestrutura, através da comparação entre o aço ferrítico estabilizado somente ao Ti e o bi-estabilizado ao $\mathrm{Ti}$ e $\mathrm{Nb}$.

\section{MATERIAIS E MÉTODOS}

Os materiais estudados nesta pesquisa foram os aços inoxidáveis ferríticos ASTM 409, mono-estabilizado com titânio $(409 \mathrm{H})$, e o bi-estabilizado com titânio e nióbio (409S). A composição química de ambos os aços está apresentada na Tabela 1. 
Tabela 1 - Composição química

\begin{tabular}{|c|c|c|c|c|c|c|c|c|}
\hline \multirow{2}{*}{ Aço } & \multicolumn{7}{|c|}{ Elementos (\% em peso) } \\
\cline { 2 - 9 } & $\% \mathrm{C}$ & $\% \mathrm{Cr}$ & $\% \mathrm{Ni}$ & $\% \mathbf{T i}$ & $\% \mathbf{N b}$ & $\% \mathrm{Mn}$ & $\% \mathrm{Si}$ & $\mathrm{N}(\mathrm{ppm})$ \\
\hline $\mathbf{4 0 9 H}$ & 0,0067 & 11,05 & 0,17 & $\mathbf{0 , 1 7 2}$ & 0,017 & 0,17 & 0,46 & 78 \\
\hline 409S & 0,0073 & 10,99 & 0,11 & $\mathbf{0 , 1 5 0}$ & $\mathbf{0 , 0 6 1}$ & 0,11 & 0,49 & 90 \\
\hline
\end{tabular}

A amostragem foi realizada após as etapas de laminação à quente com espessura de $3,00 \mathrm{~mm}$ e após a laminação a frio com redução de $60 \%$, obtendo espessura final de $1,20 \mathrm{~mm}$. As amostras laminadas a frio foram recozidas em laboratório nas temperaturas, conforme Tabela 2.

Tabela 2 - Temperaturas de tratamento térmico em Laboratório

\begin{tabular}{|c|c|c|c|}
\hline $409 \mathrm{H}$ & $409 \mathrm{~S}$ & Temperatura $\left({ }^{\circ} \mathrm{C}\right)$ & Tempo encharque (s) \\
\hline $\mathrm{H} 1$ & $\mathrm{~S} 1$ & 850 & 30 \\
\hline $\mathrm{H} 2$ & $\mathrm{~S} 2$ & 880 & 30 \\
\hline $\mathrm{H} 3$ & $\mathrm{~S} 3$ & 910 & 30 \\
\hline $\mathrm{H} 4$ & $\mathrm{~S} 4$ & 940 & 30 \\
\hline $\mathrm{H} 5$ & $\mathrm{~S} 5$ & 950 & 30 \\
\hline $\mathrm{H} 6$ & $\mathrm{~S} 6$ & 960 & 30 \\
\hline $\mathrm{H} 7$ & $\mathrm{~S} 7$ & 970 & 30 \\
\hline $\mathrm{H} 8$ & $\mathrm{~S} 8$ & 1000 & 30 \\
\hline $\mathrm{H} 9$ & $\mathrm{~S} 9$ & 1030 & 30 \\
\hline $\mathrm{H} 10$ & $\mathrm{~S} 10$ & 1060 & 30 \\
\hline $\mathrm{H} 11$ & $\mathrm{~S} 11$ & 1080 & 30 \\
\hline $\mathrm{H} 12$ & $\mathrm{~S} 12$ & 1100 & 30 \\
\hline
\end{tabular}

As análises da microestrutura foram realizadas utilizando Microscópio Ótico Leica DMRM e software Leco IA3001, na seção longitudinal a direção de laminação da chapa. Para revelação da microestrutura foi utilizado reativo Vilella com tempo de 50 segundos de ataque, sendo o tamanho de grão medido pelo método de três círculos concêntricos, conforme norma ASTM E112/13 [8].

A análise por EBSD "Electron Back Scattered Diffration" foi realizada na seção longitudinal a direção de laminação da chapa utilizando Microscópio Eletrônico de Varredura PHILIPS XL-30. Os dados foram processados usando o software OIM TM Analysis ${ }^{\circledR}$.

\section{RESULTADOS E DISCUSSÃO}

\subsection{Microestrutura Após Laminação a Quente}

As microestruturas dos aços após laminação à quente são mostradas nas Figuras 1 e 2 . 


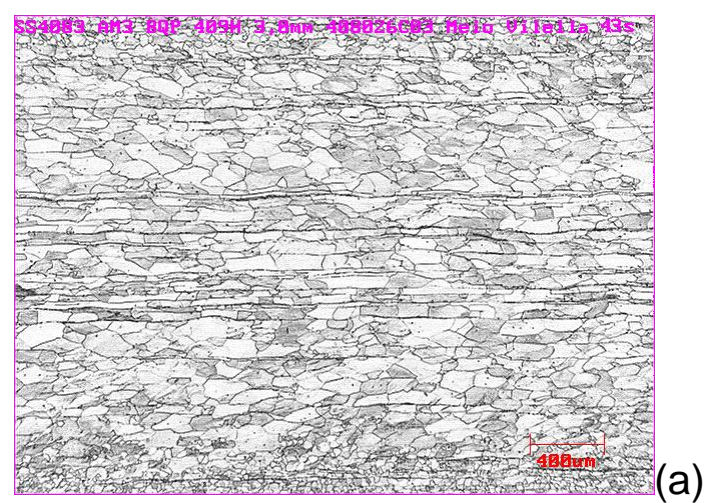

(a)

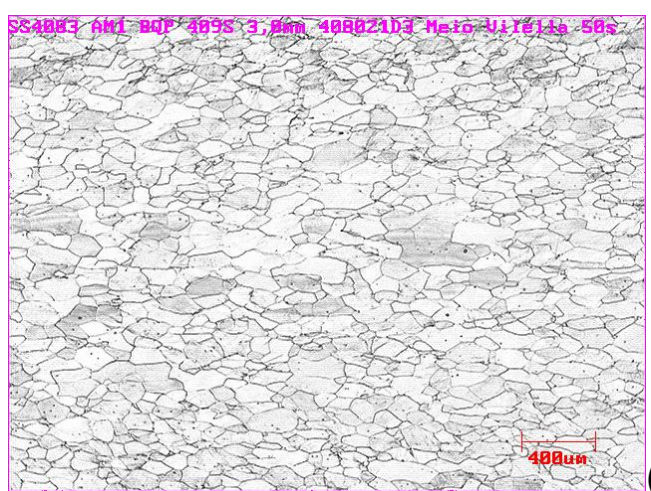

(b)

Figura 1 - Microestrutura dos aços - ao longo da espessura - aumento 100x. Aço 409H (b) Aço 409S

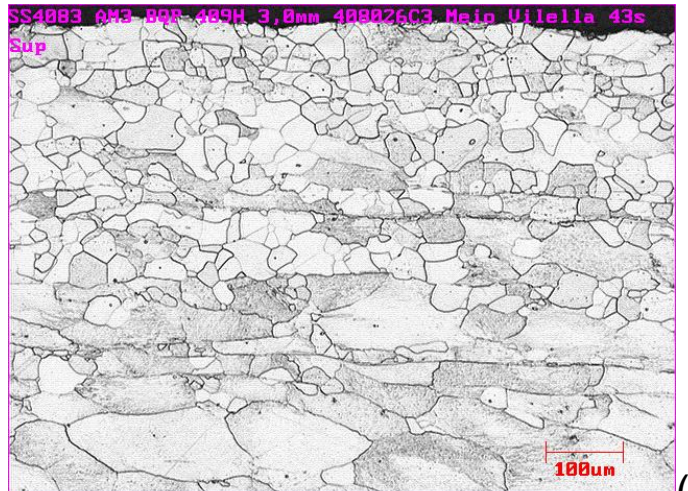

(a)

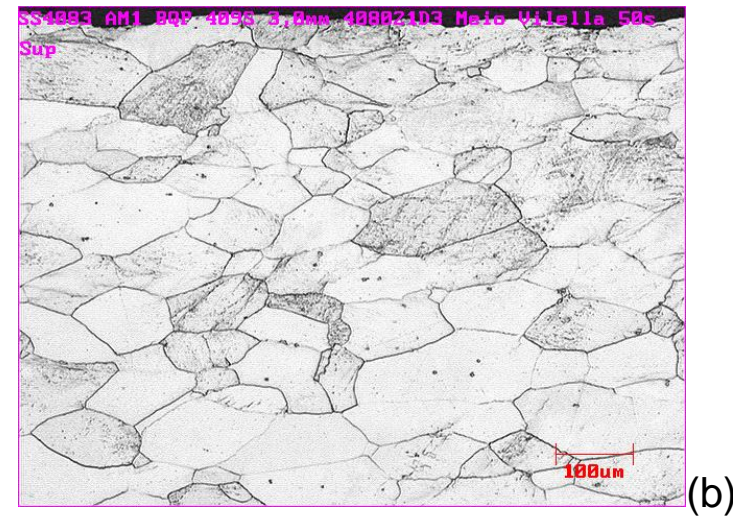

Figura 2 - Microestrutura dos aços - região da superfície - aumento 25x. Aço 409H (b) Aço 409S

Os resultados mostram que a microestrutura do aço $409 \mathrm{H}$ é constituída por um gradiente de grãos ao longo da espessura. A região central é prevalecida por grãos maiores, enquanto a superfície apresenta grãos menores com certo grau de recristalização. O aço 409S apresenta uma microestrutura de grãos mais deformados ao longo da espessura sem apresentar o mesmo gradiente.

A diferença de orientação, assim como o mapa de desorientação interna dos grãos misorientation - (GOS - grain orientation spread), considerando grãos recristalizados com ângulo $<1^{\circ}$, são mostrados na Figura 3.
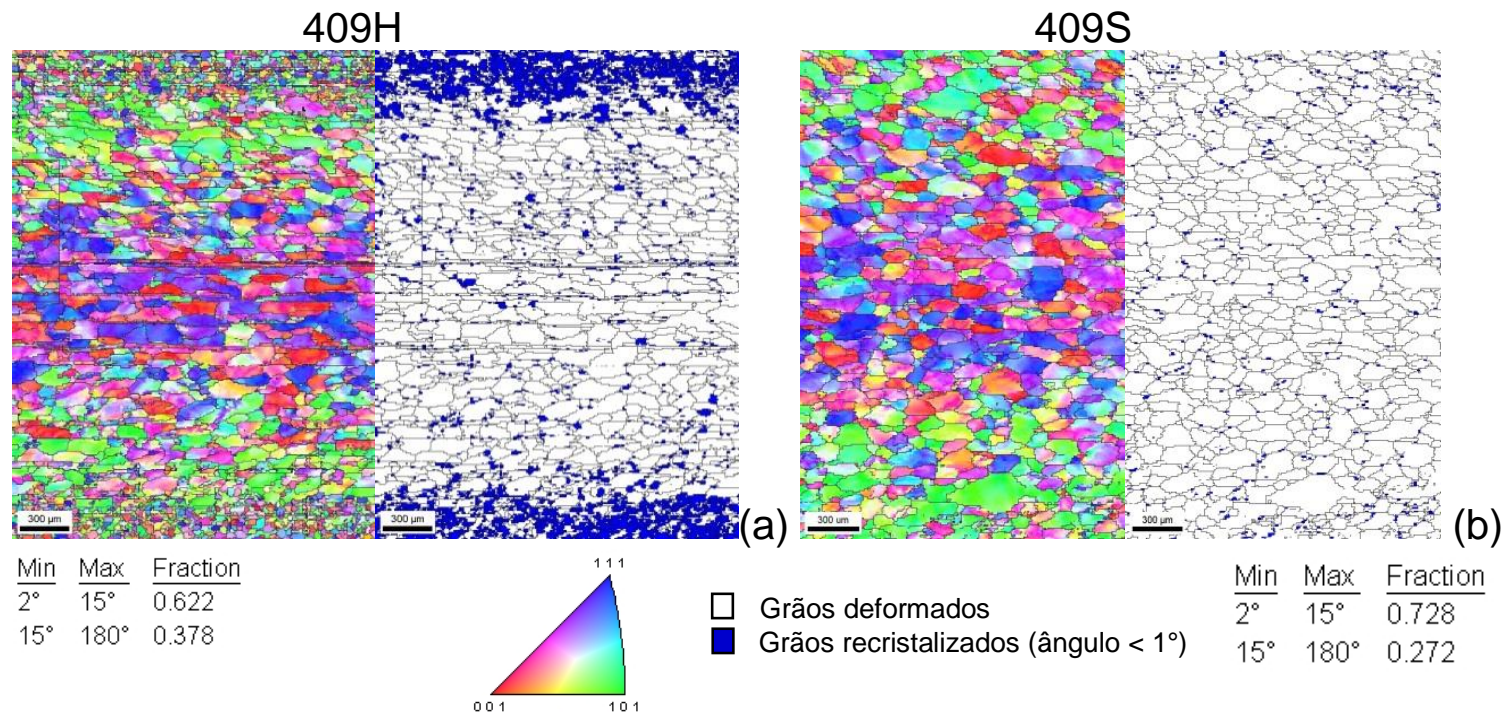

Figura 3 - Mapa de orientação e mapa de desorientação interna (misorientation) dos aços inoxidáveis ferríticos estudados. Aço 409H (b) Aço 409S 
Os resultados de metalografia apresentam boa concordância com os mapas de orientação interna dos grãos (GOS), os quais apresentam grãos mais alongados (deformados) no centro da espessura e grãos recristalizados próximo à superfície para o aço 409H. Por outro lado, o aço 409S apresenta uma maior homogeneidade nos grãos, porém com uma microestrutura mais deformada, o que pode ser comprovado pela maior fração de grãos com ângulo menor que 15․ Essa diferença de microestrutura entre os dois aços está relacionada com o efeito mais forte do nióbio em comparação ao titânio.

O teor de nióbio $(\Delta \mathrm{Nb})$ e titânio $(\Delta \mathrm{Ti})$ em solução sólida foram calculados através das Equações 1 e 2 (6).

Tabela 3 - Cálculo de Ti e Nb em solução sólida

\begin{tabular}{|c|c|c|c|c|c|c|}
\hline Aços & $\% \mathrm{Ti}$ & $\% \mathrm{Nb}$ & $\% \mathrm{C}$ & $\% \mathrm{~N}$ & $\Delta \mathbf{N b}$ & $\Delta \mathbf{T i}$ \\
\hline $\mathbf{4 0 9 H}$ & 0,172 & 0,017 & 0,007 & 0,008 & - & 0,137 \\
\hline 409S & 0,150 & 0,061 & 0,007 & 0,009 & 0,022 & 0,111 \\
\hline
\end{tabular}

$$
\begin{aligned}
& \Delta \mathrm{Nb}=\% \mathrm{Nb}-7,74 \times 0,7 \times \% \mathrm{C} \\
& \Delta \mathrm{Ti}=\% \mathrm{Ti}-4,0 \times 0,3 \times \% \mathrm{C}-3,42 \times \% \mathrm{~N}
\end{aligned}
$$

Os resultados mostram que o aço 4095 possui maior quantidade de nióbio em solução sólida, o que explica a dificuldade de migração dos contornos de grãos também pelo efeito Drag (dificuldade de arraste de impurezas pelo contorno de grão). Apesar do aço $409 \mathrm{~S}$ possuir $\mathrm{Nb}$ em solução sólida, a solubilidade deste elemento na estrutura ferrítica é 10 vezes menor que o Ti, portanto, mais $\mathrm{Nb}$ é segregado para o contorno de grão, reforçando ainda mais o efeito de arraste [6].

Embora os dois elementos ( $\mathrm{Ti}$ e $\mathrm{Nb}$ ) tenham raio atômico muito próximo, o $\mathrm{Nb}$ modifica muito mais o parâmetro de rede da estrutura cristalina que o $\mathrm{Ti}$, não estabelecendo uma relação com o tamanho dos átomos, sendo este efeito devido a interações eletrônicas, embora não completamente compreendido [6].

O efeito de retardar a recristalização, provocado pelo nióbio, resultou uma microestrutura do aço 409S mais deformada em relação ao aço $409 \mathrm{H}$, conforme resultados de maior fração de contornos de baixo ângulo apresentados na figura 3 (10\% maior).

\subsection{Microestruturas Após Recozimento em Laboratório}

As figuras 4 e 5 mostram a evolução das microestruturas dos aços estudados após tratamento térmico em laboratório. 


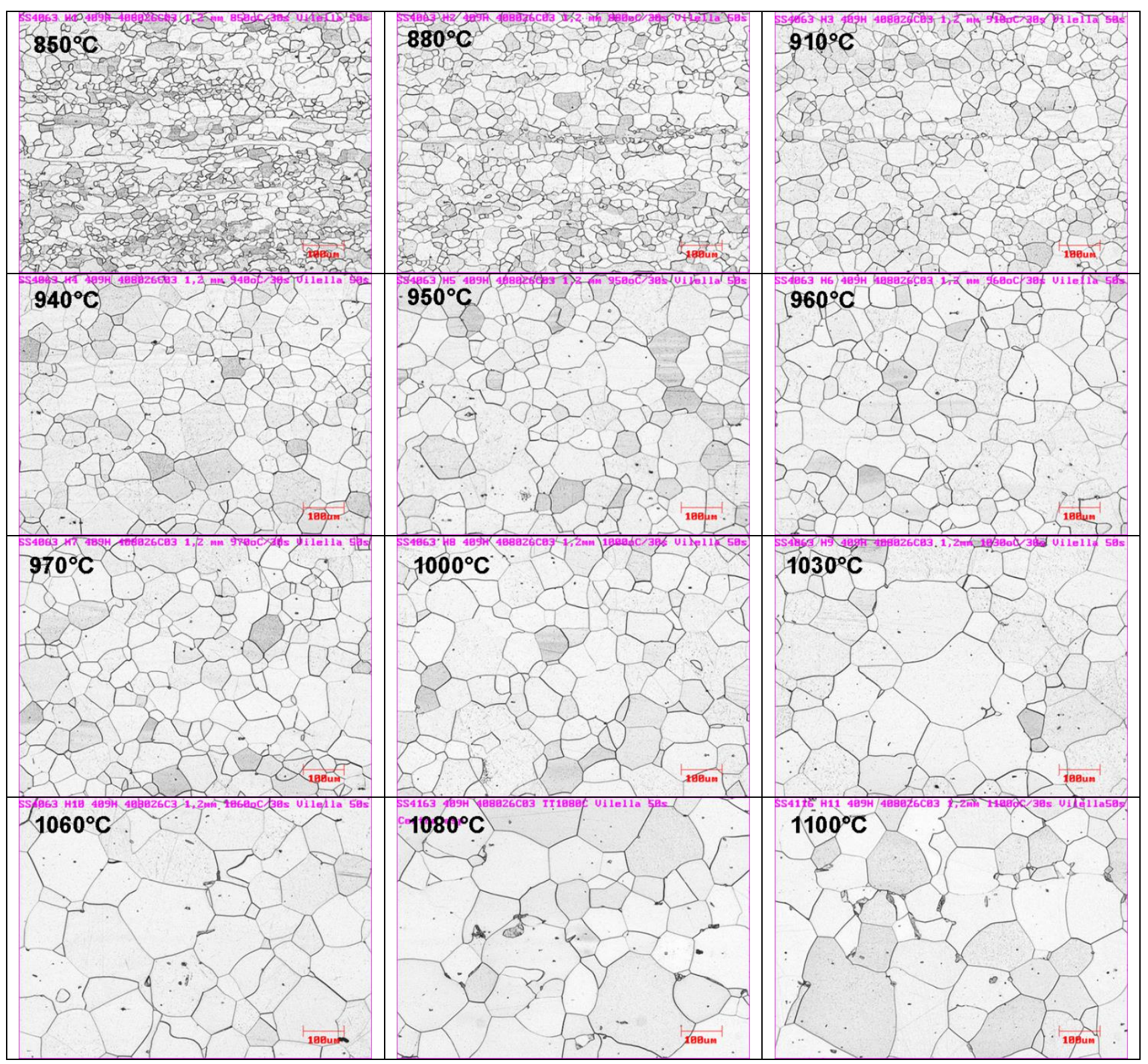

Figura 4 - Evolução da microestrutura do aço $409 \mathrm{H}$ em função da temperatura de recozimento com aumento de $100 x$ 


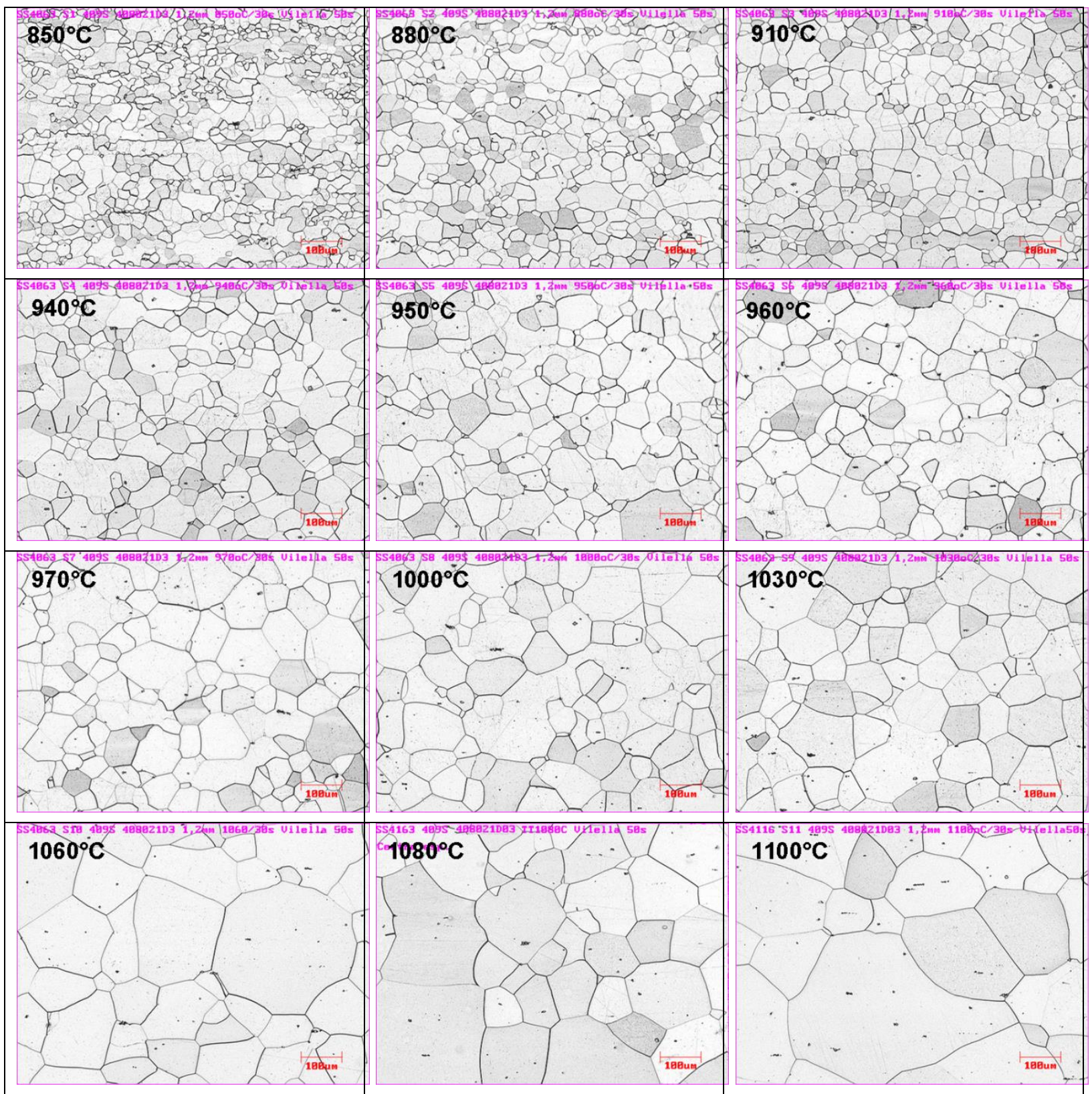

Figura 5 - Evolução da microestrutura do aço 409S em função da temperatura de recozimento com aumento de $100 x$

De acordo com as microestruturas das Figuras 4 e 5, o aço 409S apresenta grãos mais recristalizados a $880^{\circ} \mathrm{C}$, enquanto o aço $409 \mathrm{H}$ apresenta grãos recristalizados na temperatura de $940^{\circ} \mathrm{C}$.

Portanto, as análises mostram que a temperatura de recristalização do aço 409S é inferior ao do aço $409 \mathrm{H}$. Isto se deve em função da maior energia acumulada no aço 409S após laminação a frio, gerando força motriz capaz de vencer o efeito do nióbio de retardar a recristalização.

Segundo Humphreys, quanto maior a deformação prévia, menor será a temperatura de recristalização [9]. Adicionalmente, Krauss relata que a recristalização é impulsionada pela alta energia acumulada na estrutura deformada pelo trabalho a frio [10].

A Figura 6 mostra a evolução dos valores do tamanho médio de grão para os dois aços recozidos em laboratório. 


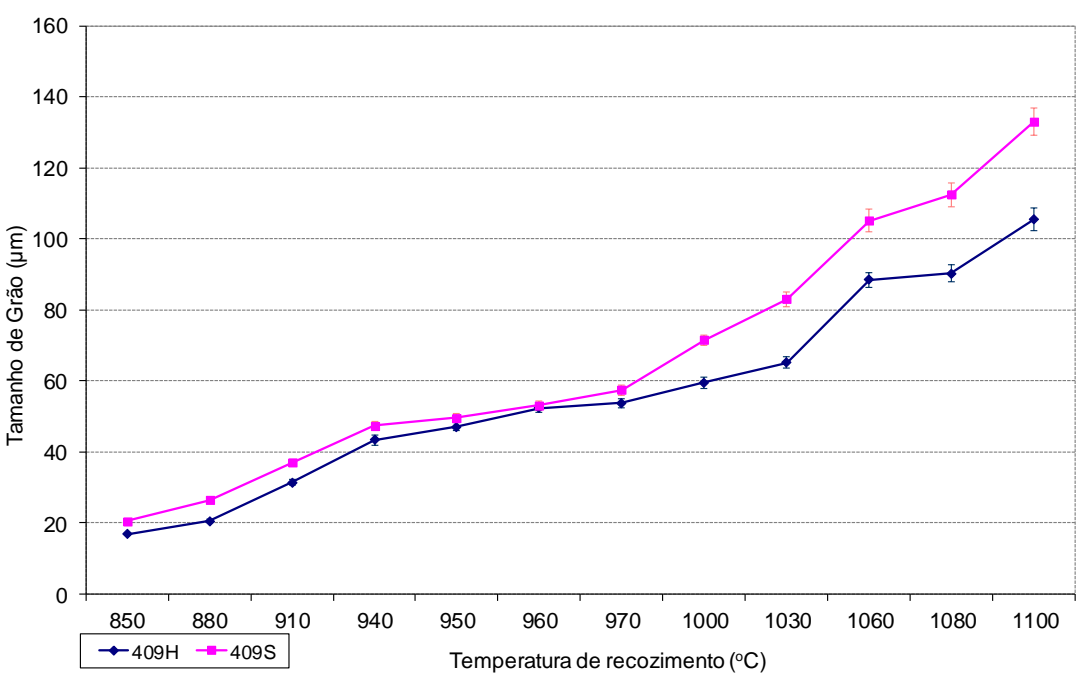

Figura 6 - Evolução do tamanho médio do grão dos aços 409H e 409S

A evolução do tamanho médio do grão em função da temperatura de recozimento, mostra que existe uma tendência de recristalização antecipada do aço 409S, o qual apresenta maior crescimento de grão. Com o término da recristalização primária, alguns grãos continuam crescendo além dos outros, o que caracteriza um crescimento anormal dos grãos (recristalização secundária) [9], conforme visto com mudança de patamar, mostrado na figura 6 . Este fenômeno ocorre para ambos os aços a partir da temperatura de $1030^{\circ} \mathrm{C}$, porém, com maior intensidade no aço $409 \mathrm{~S}$.

\section{CONCLUSÃO}

A recristalização do aço 409S ocorre em menor intensidade durante a laminação a quente, em função do teor de nióbio em solução sólida e seu efeito na mobilidade do contorno de grão (efeito de Drag), promovendo uma estrutura de grãos mais deformados e uniformes ao longo da espessura. O processo de recristalização no recozimento do aço $409 S$ é afetado diretamente pela estrutura mais deformada em relação ao aço $409 \mathrm{H}$, gerando assim, maior força motriz para recristalização no recozimento final.

\section{REFERÊNCIAS}

1 ASTM A240, Standard Specification for Chromium and Chromium-Nickel Stainless Steel Plate, Sheet, and Strip for Pressure Vessels and for General Applications. West Conshohocken : s.n., 2012. 2012.

2 FRITZ, JAMES D. e FRANSON, IVAN A., Stabilization Requeriments for 409 (UNS S40900) Ferritic Stainless Steel. 1997.

3 RAABE, D.; LÜCKE, K., Texture of ferritic stainless steels. Materials Science and Technology, v. 9, p. 302-312, Abril 1993

4 HIRAMATSU, N., MIYAKUSU, K. e UEMATSU, Y., Effects of Alloyng Elements on High Temperature Oxidation Resistance of Thin Foil of High Al Bearing Ferritic Stainless Steels. Stainless Steel'91. 1991, pp. 1227-1234.

5 SILVA, JOILSON M. FERREIRA, Melhoria da Lingotabilidade do Aço Inoxidável Ferrítico AISI 409 na Arcelormittal Inox Brasil. Belo Horizonte : s.n., 2009

6 OLIVEIRA, T. R., Effet du niobium et du titane sur la déformation à chaud d'aciers inoxydables ferritiques stabilisés. Tese (Doutorado em Ciência e Engenharia dos Materiais). 2003, École Nationale Supérieure de Minas de Saint-Etiene, p. 222. 
7 FARIA, R. A., Efeito dos Elementos Ti e Nb no Comportamento em Fadiga de Aços Inoxidáveis Ferríticos Utilizados no Sistemas de Exaustão de Veículos automotores. Tese (Doutorado em Engenharia de Materiais), 2006, Escola de Engenharia - UFOP, p. $268 \mathrm{f}$.

8 ASTM E112, Standard Test Methods for Determining Average Grain Size. West Conshohocken : s.n., 2014. 2014.

9 HUMPHREYS, F. F. e HATHERLY, M., Recrystallization and related annealing phenomena. 2 ed. Kidlington : Elsevier, 2004. pp. 1-65.

10 KRAUSS, G., Steels: Heat Treatment and Processing Principles. ASM., 2005, USA p.221-224 